\title{
Individual and Economic Characteristics as Determinants of Brazilian Runners' Motivation
}

\author{
Mabliny Thuany ${ }^{1, *(\mathbb{D})}$, Ewa Malchrowicz-Mośko ${ }^{2} \mathbb{D}$, Zbigniew Waśkiewicz $^{3,4}$ (D) $_{\text {and Thayse Natacha Gomes }}{ }^{(\mathbb{D}}$ \\ 1 Centre of Research, Education, Innovation and Intervention in Sport (CIFI2D), Faculty of Sports, \\ University of Porto, 4200-450 Porto, Portugal \\ 2 Faculty of Sport Sciences, Poznan University of Physical Education, 61-831 Poznan, Poland; \\ malchrowicz@awf.poznan.pl \\ 3 Institute of Sport Science, Jerzy Kukuczka Academy of Physical Education, 40-065 Katowice, Poland; \\ z.waskiewicz@awf.katowice.pl \\ 4 Department of Sports Medicine and Medical Rehabilitation, Sechenov University, 119991 Moscow, Russia \\ 5 Department of Physical Education, Post-Graduation Program of Physical Education, Federal University of \\ Sergipe (UFS), São Cristóvão 49100-000, Brazil; thayse_natacha@hotmail.com \\ * Correspondence: mablinysantos@gmail.com
}

Citation: Thuany, M.;

Malchrowicz-Mośko, E.; Waśkiewicz, Z; Gomes, T.N. Individual and Economic Characteristics as Determinants of Brazilian Runners' Motivation. Sustainability 2021, 13, 10178. https:// doi.org/10.3390/su131810178

Academic Editors: Guillermo Felipe López Sánchez and Lee Smith

Received: 1 August 2021

Accepted: 8 September 2021

Published: 11 September 2021

Publisher's Note: MDPI stays neutral with regard to jurisdictional claims in published maps and institutional affiliations.

Copyright: (C) 2021 by the authors. Licensee MDPI, Basel, Switzerland. This article is an open access article distributed under the terms and conditions of the Creative Commons Attribution (CC BY) license (https:// creativecommons.org/licenses/by/ $4.0 /)$.

\begin{abstract}
Due to differences in runners' profiles, which can be related to sociodemographic characteristics, motivations for running can vary. This study aimed to identify Brazilian runners' motivations for their practice, and the factors associated among runners who point to look for performance improvement as their main motivation. The sample comprised 1097 non-professional road runners. The questionnaire "Profile characterization and associated factors for runner's performance" was used. The results showed that the oldest athletes and those with the highest income levels presented lower likelihood of reporting performance improvement as their main motivation for taking part in running. In terms of income level, results showed that as this increased, there was a lower chance of getting involved in practice with a focus on incremental improvements in performance. Differences between sexes were also observed, with men more likely to indicate performance improvement as their motivation for running. In Brazil, most runners reported "health" as their main motivation for running. Women, older runners, and those with higher income levels were less likely to point to performance improvements as their main motivation for taking up running.
\end{abstract}

Keywords: running; Brazil; runners' profiles; health; performance

\section{Introduction}

Number of people aiming to improve health and fitness components through running is constantly growing all over the world, and became a social phenomenon [1]. These people lead a physically demanding lifestyle, have better mental condition and usually belong to running subcultures [2]. Some of the health benefits associated with running that have been highlighted include a decrease in the risk of developing cardiovascular disease and mortality, and improvements to important aspects of mental health (e.g., wellbeing, depression, and anxiety disorders) [3-6]. Development of sport for all is a part of a philosophy of sustainable development which focuses on improving quality of life, tackling social exclusion, increasing access, preserving the environment, and expanding the pursuit of excellence-running can serve as an example [7]. At an international level from 1986 to 2018 data covering different countries and continents showed an increment of $57.8 \%$ in the number of runners [8]. Data comprising 3961 athletes indicated that $28.76 \%$ started running also during the COVID-19 pandemic (perhaps because this sports discipline does not require close contact with other runners, which may pose a risk of contracting the virus [9]), with $72 \%$ reporting health as their main motivation for doing so [10]. In Brazilian context, data covering two of the most famous race events in the country indicated an increase in the number of enrolled runners between 2007-2015 [11]. 
Since participation in endurance events has greatly increased, understanding why those athletes get involved in different races has become one of the main research questions in literature on the subject [12]. Therefore, recent research has tended to be focused on trying to understand the motivation behind athletes in different endurance races such as the triathlon, ultramarathon, cycling or different distance running events [13]. Research into running has increased with much being carried out worldwide in relation to diverse factors linked to this practice, e.g., physical health benefits $[14,15]$, physiology and nutrition $[16,17]$ and psychological aspects of running [18-21]. Running is a worldwide phenomenon, and research into this topic has been developed in different countries, e.g., United States [22,23], Spain [24], Poland [25], and Greece [26]. Some studies have also recently compared types of motivation behind running cross culturally, in an attempt to ascertain whether there are any differences in reasons for participating between United Kingdom and Indian runners [27].

Previous studies usually reported health as an important factor associated with involvement in running, in a non-professional context [28,29]. Among Brazilian runners, similar results have been observed, with runners pointing to "health" and proxy factors as driving their motivation to begin running $[28,30,31]$. Regarding the socioeconomic status, we found that high income was inversely related to performance in non-professional runners [32]. In the reported paper, we proposed a theoretical model to explain results found, understanding that runners with lower income may become involved in running with the purpose of achieving social and financial support [30] and, as consequence, they also presented higher chances to point out looking for performance improvement as their main motivation for the practice, and also a higher training commitment. However, in the cited study, differences according to place of residence were not considered. In Brazil, studies that involve physically active population need to consider these differences, since Brazil is one of the biggest countries in the world (i.e., in both, dimension and population size), split in 26 states, which are organized into five regions (Southeast, South, Northeast, North, and Midwest). In addition, there are inter-states differences related to urban design, cultural, economic, and sociodemographic characteristics, as well as in sports investment, number of running events and distribution of the best elite athletes, that can lead to differences in runners' profiles, that can be linked to sociodemographic characteristics and motivations for running practice (or another sports practice) [31]. Thus, the purpose of this study is to identify Brazilian runners' motivations for their practice, and the factors associated with runners who point performance as their main motivation, adopting states as cluster. Based upon previous results, we hypothesized that runners with high incomes and the elderly are more likely to point "health" as their motivation for running practice.

\section{Materials and Methods}

\subsection{Ethical Approval}

The study followed the Declaration of Helsinki statements and was approved by the Ethics Committee of the Federal University of Sergipe, Brazil (protocol $n^{\circ}$ 3.558.630). All participants were informed about the study purposes, procedures, benefits and risks, and also the possibility to check the study's ethical aspect. Only runners who signed the consent form to take part in the study were included.

\subsection{Design and Sample}

The sample comes from participants enrolled in the InTrack project [33]. To be included in the study, participants should self-classify as runner and answer the online questionnaire used to obtain information. Participants who did not give their informed consent to study participation, and/or were aged below 18 years, and did not provide answer (or provided a non-sense answer) for the mandatory questions (i.e., running pace, training frequency, running motivation) were not considered in the present study. The final sample for the present study comprised 1097 non-professional road runners (mean age: $38.08 \pm 9.41$ years; mean body mass: $70.9 \pm 12.6 \mathrm{~kg}$; mean body mass index (BMI): $24.3 \pm 3.20 \mathrm{~kg} \cdot \mathrm{m}^{2}$ ), which were sampled for convenience, living in the five Brazilian regions. 


\subsection{Data Collection}

The questionnaire "Profile characterization and associated factors for runner's performance" was developed, and previously validated before its use in the study [34]. The questionnaire was sent and available for those who were eligible to be included in the study via an online platform (Google forms) and through social media, between November 2019 and March 2020. The information used in the present study is listed below.

\subsection{Individual Characteristics}

\subsubsection{Sociodemographic Information}

Information related to runners' sex, age, height, and weight were self-reported, and BMI was computed [weight $(\mathrm{kg}) /$ height $\left(\mathrm{m}^{2}\right)$ ]. A previous study demonstrated the accuracy of runners' self-reported heights and weights [35].

Age: Runners were categorized into different age intervals that included young adults (18-29 years); adults ( $30-39$ years); early middle-aged ( $40-49)$; older adults ( $50-59$ years); and seniors ( $\geq 60$ years). These age categories were based on a previous study conducted on two of the main Brazilian race events [32].

State of residence and socioeconomic status (SES): runners indicated their estimated monthly income, based on the Brazilian minimum wage in 2019 [36]. For the present analysis, answers were split into the categories: "Low" ( $\leq \mathrm{R} \$ 998.00$ or about $\leq 241.06 \mathrm{US} \$$ ), "Medium" ( $>$ R $\$ 998.00$ - $\leq \mathrm{R} \$ 2994.00$ or about $>241.06$ US\$ - $\leq 723.18$ US\$), "Medium-high" ( $>\mathrm{R} \$ 2994.00-\leq \mathrm{R} \$ 4990.00$ or about $>723.18$ US $\$-\leq 1205 \mathrm{US} \$$ ) and "High" (>R $\$ 4990.00$ or about $>1205$ US\$).

\subsubsection{Training Variables}

Running pace (s $/ \mathrm{km})$ : Runners reported the time taken to cover one kilometer within a preferred distance ( $5 \mathrm{~km}, 10 \mathrm{~km}$, half-marathon, and marathon). This information was used for sample characterization.

Motivation for the practice: runners indicated their main motivation for practice from the following options: performance, health and quality of life, physical conditioning, social interaction, competition participation. Categories were dichotomized into "performance" (performance, physical conditioning, and competition participation) or "health" (health and quality of life, social interaction).

Frequency of training: runners informed the number of training sessions they usually complete per week (2-7 training units/week). The variable was considered in counts.

Volume/week: runners indicated the average total distance (in kilometers) they cover in a typical weekly training sessions.

Practice time: runners were grouped into two classes, namely "up to one year" of practice or "more than one year" of practice time.

\subsection{Statistical Analyses}

Descriptive statistics are presented as mean \pm standard deviation (SD) for continuous variables and frequencies (\%) to categorical variable. Logistic regression, considering the state of residence as a cluster, was used to identify the variables associated with the chances of runners point out "performance" improvement as the main motivation for running. A model was built considering sex, age interval, and economic level as predictors. All analyses were undertaken using STATA V.14.0 software (STATA Corp, College Station, TX, USA), with a $95 \%$ confidence level.

\section{Results}

Descriptive results are presented in Table 1, taking into account the motivation for running categories. When observed alongside the age groups, it is observed that with increasing age, there is an increase in the frequency of runners who indicated running for health benefits. Similar results are observed when taking into account the SES - the 
higher the SES is, the lower the frequency of subjects that indicate performance as their main motivation.

Table 1. Descriptive information for practice motivation.

\begin{tabular}{|c|c|c|c|}
\hline & Health & Performance & Missing \\
\hline \multicolumn{4}{|l|}{ Age categories } \\
\hline $18-29$ y $(n=273)$ & $155(56.8 \%)$ & $115(42.1 \%)$ & $3(1.1 \%)$ \\
\hline $30-39$ y $(n=358)$ & $253(70.7 \%)$ & $103(28.8 \%)$ & $2(0.6 \%)$ \\
\hline $40-49$ y $(n=237)$ & $190(80.2 \%)$ & $46(19.4 \%)$ & $1(0.4 \%)$ \\
\hline $50-59$ y $(\mathrm{n}=103)$ & $91(88.3 \%)$ & $12(11.7 \%)$ & \\
\hline$\geq 60 y(n=126)$ & $97(77 \%)$ & $27(21.4 \%)$ & $2(1.6 \%)$ \\
\hline $\begin{array}{l}\text { Training frequency } \\
\text { (session/week) }\end{array}$ & $3.2(1.25)$ & $3.8(1.6)$ & \\
\hline Training volume (km/week) & $30.6(22.6)$ & $40.8(28.9)$ & \\
\hline Running pace (min:sec) & $5: 43(56.9)$ & $4: 55(66.3)$ & \\
\hline \multicolumn{4}{|l|}{ SES } \\
\hline Low $(n=67)$ & $32(47.8 \%)$ & $34(50.7 \%)$ & $1(1.5 \%)$ \\
\hline Medium $(n=284)$ & $178(62.7 \%)$ & $102(35.9 \%)$ & $4(1.4 \%)$ \\
\hline Medium-high $(\mathrm{n}=228)$ & $175(76.8 \%)$ & $53(23.2 \%)$ & \\
\hline $\operatorname{High}(n=504)$ & $391(77.6 \%)$ & $110(21.8 \%)$ & $3(0.6 \%)$ \\
\hline Missing & & & $14(1.3 \%)$ \\
\hline \multicolumn{4}{|l|}{ Practice time } \\
\hline$\leq 1$ year $(\mathrm{n}=173)$ & $115(66.5 \%)$ & $54(31.2 \%)$ & $4(2.3 \%)$ \\
\hline$>1$ year $(\mathrm{n}=922)$ & $670(72.7 \%)$ & $248(26.9 \%)$ & $4(0.4 \%)$ \\
\hline Missing & $1(0.3 \%)$ & $1(0.3 \%)$ & \\
\hline
\end{tabular}

Figure 1 presents the frequency of running motivation by state of residence. Athletes from Maranhão were those with the highest percentage of subjects who pointed performance as their main motivation, followed by Ceara and Acre. On the other hand, athletes from Roraima, Rio de Janeiro, and Rondônia most frequently reported health as the major factor associated with running practice.
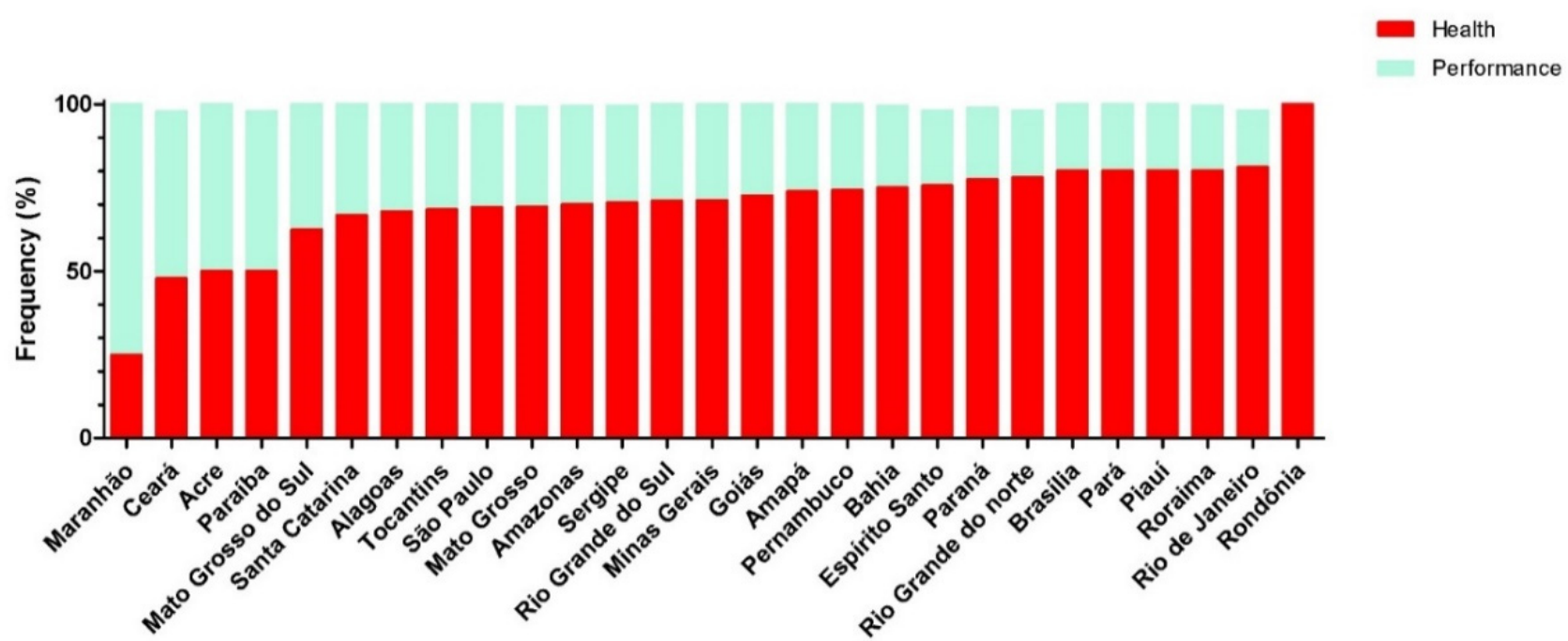

Figure 1. Practice motivation of Brazilian runners of different states.

Results from the logistic regression, clustered by states, are presented in Table 2. Men were twice as likely as women to engage in running due to performance aims $(\mathrm{OR}=2.09$; $95 \% \mathrm{CI}=1.53-2.87)$. Increasing SES $(\mathrm{OR}=0.74 ; 95 \% \mathrm{CI}=0.62-0.86)$ and age $(\mathrm{OR}=0.75$; $95 \% \mathrm{CI}=0.65-0.86)$ decreased the chances of athletes pointing performance as their motivation for practice. The model explained $6 \%$ of the variance in motivation for practice among runners. 
Table 2. Logistic regression, to chances to running for performance, considering states with a cluster.

\begin{tabular}{ccccc}
\hline Variables & OR & SD & $p$-Value & CI95\% \\
\hline Sex (man) & 2.09 & 0.34 & $<0.001$ & $1.53-2.87$ \\
SES & 0.74 & 0.07 & 0.002 & $0.62-0.90$ \\
Age category & 0.75 & 0.05 & $<0.001$ & $0.65-0.86$ \\
Constant & 0.64 & 0.13 & 0.032 & $0.43-0.96$ \\
\hline
\end{tabular}

Note: OR-Odds ratio; SES—Socioeconomic status; SD—Standard deviation; CI95\%—Confidence Interval 95\%.

\section{Discussion}

The main goal of this study was to identify the most important motivation for running practice among Brazilian runners, and the factors associated with runners pointing performance as their main motivation. Considering states as a cluster is a new approach in comparison to previous studies. In the present study, this adjustment was performed due to the fact that runners came from different states, and these states were different regarding economic, social, and environmental characteristics.

Based on previous studies, we hypothesized that runners with high-income levels and the elderly would be less likely to point performance as their main motivation for running practice. The results found were in agreement with this hypothesis, since the oldest athletes and those with the highest income levels presented a lower likelihood of reporting performance as their main motivation for taking part in running. These results are in accordance with published studies that pointed age as an important factor for motivation $[37,38]$. In this sense, young runners are more focused on getting "better results" in sports practice, while older ones take part in practice with the aim of improving their social interactions, mental health, and well-being [26].

In the research field that deals with the social class as determinants of sport practice, it is not observed many studies about running [39]. In our study, regarding income level, results showed that increasing the income level, decreases the chances of getting involved in practice with a focus on improvements in performance. Similar results were found in a previous study, where this variable was negatively associated with performance among Brazilian runners [32]. These results can be associated with changes in runners' profiles observed during recent decades [40]. Marathon statistics between 2008-2018 showed an increment of $49 \%$ in the number of participants, but a reduction in running pace of 3:55 min [41]. Data covering 70 thousand events from 1986 to 2018 showed a slowdown of $\approx 40 \mathrm{~min}$ in time taken to complete a Marathon, with an incremental increase in mean age (from 35.2 years in 1986 to 39.3 years in 2018). These variations are associated with changes in motivation for participating in running - from achieving personal bests to improving health, well-being, and social factors [9]. Furthermore, these data can be confirmed through the number of runners who travel to take part in race events [42], the rising in the number of thematic events, and the economic tourism associated with participation in these events [43].

Regarding income levels, a different scenario is observed among African runners, as the motivation to become an elite athlete is associated with a desire to raise the income level and economic conditions [44]. These results are associated with specific conditions and cultural aspects observed among African athletes. On the other hand, in Brazil, for the most of non-professional athletes, running is associated with being a recreational leisure practice, while soccer is perceived as the main sport associated with economical-social ascension [45].

According to Stempel (2005), the highest economic classes in the United States use such sports as recreational running to build barriers to differentiate them from those from the lowest classes. Based on the ideology of healthism in Western societies, the distinctive feature is care for the body, health and physical condition, which makes it possible to distinguish itself from inactive and lazy lower classes [46,47]. In the Western countries, subjects from the middle- and upper-classes are the primary participants at non-elite level distance running [48]. 
Differences between sexes were also observed, with men more likely to indicate performance as their motivation for running. These results are similar to those observed in a recent systematic review, where authors reported the same sex difference with men scoring higher on competition and challenge or achievement reasons in comparison to women [49]. Results from Polish marathon runners indicated that among female marathoners weight concern, affiliation, coping psychologically, life meaning, and self-esteem were the factors most cited as their motivation. Results for male runners showed a higher motivation for competition [50]. Another significant difference between sexes appeared in the reasons of desire to get away from everyday life and its prevailing fashion, which were more important for women than for men [51]. These differences can partially explain the differences in performances between sexes, given that athletes motivated by competition tend to present more commitment to training, leading to better performance [32].

This paper has some limitations. Firstly, notwithstanding the large diversity in motivation for the practice of a given sport, we used a dichotomous variable, presenting just two categories (health and performance). Although we understand this limitation, we are confident that these two domains capture a large number of possibilities; previous studies generally point these two as the most relevant in the context of sports practice. Secondly, the sample distribution was not homogenous across states, which may limit the generalization of results. Separately, in recent years researchers' interest to understand motivations for involvement in sports has increased, due to its relevance for exercise practice maintenance [52]. One of the main concerns driving this interest is the increase in the incidence of diseases associated with low physical activity levels, meaning that involvement in sports practice can act as a public health strategy, due to its possibility of improving health and quality of life of its practitioners and also the broader population. Moreover, this can also contribute to the local economy, through the sustainable development of sports tourism and the organization of sports events [53].

\section{Conclusions}

The results of the present study point that in Brazil, most runners reported "health" as their main motivation for running. When running performance motivation was analyzed considering state as a cluster, we showed that women, older runners, and those with higher income levels were less likely to point to improvements in the performance as their main motivation for taking up running. Future studies could investigate motivations for running practice and participation in events, considering differences between events that are free of charge and those that require payment to take part. Besides that, information on different levels could be considered, for example, differences in runners' profiles according to club participation, country, or continent of practitioners' origin or residence.

Author Contributions: Conceptualization, M.T. and T.N.G.; methodology, M.T. and T.N.G.; software, M.T. and T.N.G.; validation, M.T. and T.N.G.; formal analysis, M.T. and T.N.G.; investigation, M.T. and T.N.G.; resources, M.T. and T.N.G.; data curation, M.T. and T.N.G.; writing_original draft preparation, M.T.; T.N.G.; E.M.-M., Z.W.; writing—review and editing, M.T.; T.N.G.; E.M.-M.; Z.W.; visualization, M.T. and T.N.G.; supervision, M.T. and T.N.G.; project administration, M.T. and T.N.G. All authors have read and agreed to the published version of the manuscript.

Funding: This research received no external funding.

Institutional Review Board Statement: The study was conducted according to the guidelines of the Declaration of Helsinki, and approved by the Ethics Committee of the Federal University of Sergipe, Brazil (protocol n 3.558.630).

Informed Consent Statement: Informed consent was obtained from all subjects involved in the study.

Data Availability Statement: The raw data supporting the conclusions of this article will be made available by the authors, without undue reservation, to any qualified researcher.

Conflicts of Interest: The authors declare no conflict of interest. 


\section{References}

1. Abbas, A. The embodiment of class, gender and age through leisure: A realist analysis of long distance running. Leis. Stud. 2004, 23, 159-175. [CrossRef]

2. O'Keefe, J.H.; O’Keefe, E.L.; Lavie, C.J. The Goldilocks Zone for Exercise: Not Too Little, Not Too Much. Mo. Med. 2018, 115, 98-105. [PubMed]

3. Lee, D.-C.; Pate, R.R.; Lavie, C.J.; Sui, X.; Church, T.S.; Blair, S.N. Leisure-time running reduces all-cause and cardiovascular mortality risk. J. Am. Coll. Cardiol. 2014, 64, 472-481. [CrossRef] [PubMed]

4. Santos, C.S.S.D.; Sousa, V.G.S.D.; Neto, E.M.M. Efeitos do Treinamento Físico Sobre Parâmetros de Saúde de Corredores de Rua Recreacionais. Rev. Bras. Cien. Mov. 2020, 28, 107-116. [CrossRef]

5. Skead, N.; Rogers, S. Running to well-being: A comparative study on the impact of exercise on the physical and mental health of law and psychology students. Int. J. Law Psychiatry 2016, 49, 66-74. [CrossRef]

6. Gronek, P.; Wieliński, D.; Cyganski, P.; Rynkiewicz, A.; Zając, A.; Maszczyk, A.; Gronek, J.; Podstawski, R.; Czarny, W.; Balko, S.; et al. A Review of Exercise as Medicine in Cardiovascular Disease: Pathology and Mechanism. Aging Dis. 2020, 11, 327-340. [CrossRef]

7. Kazimierczak, M.; Dabrowska, A.; Adamczewska, K.; Malchrowicz-Mośko, E. The impact of modern ultramarathons on shaping social identity of runners. The case study of Karkonosze Winter Ultramarathon. Int. J. Environ. Res. Public Health 2019, 17, 116. [CrossRef] [PubMed]

8. Andersen, J.J. The State of Running 2019. Available online: https:/ / runrepeat.com/state-of-running (accessed on 21 July 2021 ).

9. Al Attar, W.S.; Husain, M. How did athletes train and avoid injuries during the COVID-19 quarantine period? Trends Sport Sci. 2021, 28, 109-115. [CrossRef]

10. Rizzo, N. Running Boom: $28.76 \%$ of Runners Started during the Pandemic. Available online: https://runrepeat.com/newpandemic-runners (accessed on 9 September 2021).

11. Thuany, M.; Gomes, T.N.; Estevam, L.C.; Almeida, M.B. Crescimento do número de corridas de rua e perfil dos participantes no Brasil. In Atividade Física, Esporte e Saúde: Temas Emergentes; Rbf editora: Belém-PA, Brazil, 2021; Volume 1.

12. Nikolaidis, P.T.; Knechtle, B.; Quartiroli, A. Who Runs? Psychological, Physiological and Pathophysiological Aspects of Recreational Endurance Athletes. Front. Psychol. 2020, 11, 2247. [CrossRef]

13. Hanson, N.; Madaras, L.; Dicke, J.; Buckworth, J. Motivational Differences Between Half, Full and Ultramarathoners. J. Sport Behav. 2015, 38, 180-191.

14. Kozlovskaia, M.; Vlahovich, N.; Rathbone, E.; Manzanero, S.; Keogh, J.; Hughes, D.C. A profile of health, lifestyle and training habits of 4720 Australian recreational runners-The case for promoting running for health benefits. Health Promot. J. Austr. 2019, 30, 172-179. [CrossRef]

15. Tapia-Serrano, M.A.; Leon-Guereno, P.; Sanchez-Miguel, P.A. Relationship Between Motivational Mechanisms, Expected Sports Performance and Perceived Health Status in Long-Distance Runners: A Mediation Model. S. Afr. J. Res. Sport Phys. Educ. Recreat. 2020, 42, 121-132.

16. Hammer, C.; Podlog, L. Motivation and marathon running. In Marathon Running: Physiology, Psychology, Nutrition and Training Aspects; Zinner, C., Sperlich, B., Eds.; Springer: Cham, Switzerland, 2016; pp. 107-124.

17. Mielgo-Ayuso, J.; Calleja-González, J.; Refoyo, I.; León-Guereño, P.; Cordova, A.; Del Coso, J. Exercise-Induced Muscle Damage and Cardiac Stress During a Marathon Could be Associated with Dietary Intake During the Week Before the Race. Nutrients 2020, 12, 316. [CrossRef] [PubMed]

18. Boudreau, A.L.; Giorgi, B. The experience of self-discovery and mental change in female novice athletes in connection to marathon running. J. Phenomen Psychol. 2010, 41, 234-267.

19. Larumbe, E.; Pérez-Llantada, M.C.; López de la Llave, A. Características del estado psicológico de los corredores populares de maratón. Rev. De Psicol. Del. Deporte 2009, 18, 151-163.

20. Raglin, J.S. The psychology of the marathoner. Sports Med. 2007, 4-5, 404-407. [CrossRef] [PubMed]

21. Summers, J.J.; Machine, V.J.; Sargent, G.I. Psychosocial factors related to marathon running. J. Sport Psychol. $1983,5,314-331$. [CrossRef]

22. Ogles, B.M.; Masters, K.S. Older vs. Younger Adult Male Marathon Runners: Participative Motives and Training Habits. J. Sport Behav. 2000, 23, 130-143.

23. Ogles, B.M.; Masters, K.S. A typology of marathon runners based on cluster analysis on motivations. J. Sport Behav. 2003, 26, 69-85.

24. Ruiz-Juan, F.; Zarauz Sancho, A. Analysis of motivation amongst Spanish marathon runners. Rev. Lat. Psicol. 2014, 46, 1-11. [CrossRef]

25. León-Guereño, P.; Tapia-Serrano, M.A.; Castañeda-Barbarro, A.; Malchrowicz-Mośko, E. Do Sex, Age, and Marital Status Influence the Motivations of Amateur Marathon Runners? The Poznan Marathon Case Study. Front. Psychol. 2020, 11, 2151. [CrossRef] [PubMed]

26. Nikolaidis, P.; Chalabaev, A.; Rosemann, T.; Knechtle, B. Motivation in the Athens classic marathon: The role of sex, age, and performance level in Greek recreational marathon runners. Int. J. Environ. Res. Public Health 2019, 16, 2549. [CrossRef] [PubMed]

27. Whitehead, A.E.; Umeh, K.; Brockett, C.; Westerbeek, H.; Powling, E.; Davies, K.F.; Rudd, J. Motivational differences between 5K, half marathon and full marathon participants in the UK and India. Manag. Sport Leis. 2020, 1-14. [CrossRef] 
28. Gratão, O.; Rocha, C. Dimensões da motivação para correr e para participar de eventos de corrida. Rev. Bras. De Ciência E Mov. 2016, 24, 90-102. [CrossRef]

29. Silva, P.N.; Solera, B.; Anversa, A.L.B.; Almeida, T.L.; Manoel, F.A. Motivação para a prática da corrida de rua: Diferença entre atletas amadores de alta performance e atletas amadores. Phys. Educ. Sport J. 2019, 7, 21-27. [CrossRef]

30. Balbinotti, M.A.A.; Gonçalves, G.H.T.; Klering, R.T.; Wiethaeuper, D.; Balbinotti, C.A.A. Perfis motivacionais de corredores de rua com diferentes tempos de prática. Rev. Bras. De Ciências Do Esporte 2015, 37, 65-73. [CrossRef]

31. Thuany, M.; Gomes, T.N.; Almeida, M.B. Is there any difference between "amateur" and "recreational" runners? A latent class analysis. Mot. Rio Claro 2020, 26. [CrossRef]

32. Thuany, M.; Gomes, T.N.; Hill, L.; Rosemann, T.J.; Knechtle, B.; Almeida, M.B.d. Running performance variability among runners from different Brazilian states: A multilevel approach. Int. J. Environ. Res. Public Health 2021, 18, 3781. [CrossRef] [PubMed]

33. InTrack Project, Welcome to InTrack Project 2021. Available online: https://intrackproject.wixsite.com/website (accessed on 9 September 2021).

34. Thuany, M.; Gomes, T.N.; Almeida, M.B. Validação de um instrumento para caracterização e verificação de fatores associados ao desempenho de corredores de rua. Sci. Plena 2020, 16, 1-7. [CrossRef]

35. Nikolaidis, P.; Knechtle, B. Validity of recreational marathon runners' self-reported anthropometric data. Percept. Mot. Ski. 2020, 127, 1068-1078. [CrossRef]

36. Brasil, R.F.D. Decreto $n^{\circ}$ 9.661, de $1^{\circ}$ de Janeiro de 2019. Diário Oficial da União. Available online: http:/ /www.in.gov.br/ materia/- /asset_publisher/Kujrw0TZC2Mb/content/id/57510734/do1esp-2019-01-01-decreto-n-9-661-de-1-de-janeiro-de2019-57510684 (accessed on 9 September 2021).

37. Netz, Y.; Raviv, S. Age differences in motivational orientation toward physical activity: An application of social—cognitive theory. J. Psychol. Interdiscip Appl. 2004, 138, 35-48. [CrossRef]

38. Poczta, J.; Malchrowicz-Mośko, E.; Fadigas, A.B.M. Age-related motives in mass running events participation. Olimp. J. Olymp. Stud. 2018, 2, 257-273.

39. Lenartowicz, M. Klasowe uwarunkowania sportu z perspektywy teoretycznej Pierre'a Bourdieu. Cult. Soc. 2012, 3, 51-74. [CrossRef]

40. Vitti, A.; Nikolaidis, P.T.; Villiger, E.; Onywera, V.; Knechtle, B. The “New York City Marathon": Participation and performance trends of 1.2M runners during half-century. Res. Sports Med. 2019, 28, 121-137. [CrossRef]

41. RunRepeat, Marathon Statistics 2019 Worldwide. Available online: https:/ / runrepeat.com/research-marathon-performanceacross-nations (accessed on 9 September 2021).

42. Thuany, M.; Knechtle, B.; Rosemann, T.; Almeida, M.B.; Gomes, T.N. Running around the Country: An Analysis of the Running Phenomenon among Brazilian Runners. Int. J. Environ. Res. Public Health 2021, 18, 6610. [CrossRef]

43. Tendências do Mercado de Corrida de Rua, Boletim de Tendência 2018. Available online: https://sebraeinteligenciasetorial. com.br/produtos/boletins-de-tendencia/tendencias-do-mercado-de-corridas-de-rua/5b5a1605d0a9751800f2af49 (accessed on 9 September 2021).

44. Onywera, V.; Scott, R.A.; Boit, M.K.; Pitsiladis, Y.P. Demographic characteristics of elite Kenyan endurance runners. J. Sports Sci. 2006, 24, 415-422. [CrossRef]

45. Costa, I.T.; Cardoso, F.S.L.; Garganta, J. O Índice de Desenvolvimento Humano e a Data de Nascimento podem condicionar a ascensão de jogadores de Futebol ao alto nível de rendimento? Mot. Rio Claro 2013, 19, 34-45. [CrossRef]

46. Stempel, C. Adult participation sports as cultural capital-A test of Bourdieu's theory of the field of sports. Int. Rev. Sociol. Sport 2005, 40, 411-432. [CrossRef]

47. Borowiec, A.; Lignowska, I. Czy ideologia healthismu jest cechą dystynktywną klasy średniej w Polsce? Cult. Soc. 2012, 3, 95-111. [CrossRef]

48. Bridel, W.; Markula, P.; Denison, J. Critical Consideration of Runners and Running. In Endurance Running-A Socio-Cultural Examination; Bridel, W., Markula, P., Denison, J., Eds.; Routledge: London, UK, 2016.

49. Pereira, H.V.; Palmeira, A.L.; Encantado, J.; Marques, M.M.; Santos, I.; Carraça, E.V.; Teixeira, P.J. Systematic review of psychological and behavioral correlates of recreational running. Front. Psychol. 2021, 12, 1162. [CrossRef] [PubMed]

50. Waśkiewicz, Z.; Nikolaidis, P.T.; Gerasimuk, D.; Borysiuk, Z.; Rosemann, T.; Knechtle, B. What Motivates Successful Marathon Runners? The Role of Sex, Age, Education, and Training Experience in Polish Runners. Front. Psychol. 2019, 25, 1671. [CrossRef] [PubMed]

51. Malchrowicz-Mośko, E.; Poczta, J. Running as a Form of Therapy Socio-Psychological Functions of Mass Running Events for Men and Women. Int. J. Environ. Res. Public Health 2018, 15, 2262. [CrossRef] [PubMed]

52. Malchrowicz-Mosko, E.; León-Guereño, P.; Tapia-Serrano, M.A.; Sánchez-Miguel, P.A.; Waśkiewicz, Z. What encourages physically inactive people to start running? An analysis of motivations to participate in parkrun and city trail in Poland. Front. Public Health 2020, 8, 717. [CrossRef] [PubMed]

53. Malchrowicz-Mośko, E.; Poczta, J. A Small-Scale Event and a Big Impact-Is This Relationship Possible in the World of Sport? The Meaning of Heritage Sporting Events for Sustainable Development of Tourism-Experiences from Poland. Sustainability 2018, 10, 4289. [CrossRef] 